\title{
Reward and Recognition Programs at Sona Koyo Steering System Ltd.
}

\author{
Neeraj Kumari \\ Faculty of Engineering \& Technology, Manav Rachna International Institute of Research and Studies (Deemed to be University), \\ NAAC Accredited 'A' Grade University, Faridabad, India
}

Received May 21, 2020; Revised June 27, 2020; Accepted July 29, 2020

Copyright $\mathrm{C} 2020$ by authors, all rights reserved. Authors agree that this article remains permanently open access under the terms of the Creative Commons Attribution License 4.0 International License

\begin{abstract}
Employee recognition is the communication tool that reinforces and rewards the most important asset that is manpower for business. Reward and recognition program are designed to reward employees who have excelled in their work and convey sincere "thank you" for a specific job well done. The study aims to find out the extent to which reward and recognition practices are implemented in Sona Koyo Steering System Ltd. A structured questionnaire was drafted comprising of both open and closed ended questions. It had 21 items in total. The questionnaire was filled by the employees of Sona Koyo Steering System Ltd., Gurugram who were selected on the basis of random sampling. The sample size is 50. To conclude, the organization provides both types of rewards; monetary and non-monetary, but nowadays most of the organizations are giving non-monetary rewards like promotion, increment in benefits, gift packs and so on because these are highly preferred by the employees. A maximum number of the organizations fixes $10 \%$ to $15 \%$ of its revenue for reward and recognition. Decisions from the top officials are considered for the employee selection for reward. Rotation of the job is done in many organizations so as to improve the performance of the employee. The best way to recognize the employees is in the group.
\end{abstract}

Keywords Motivation, Satisfied Workforce, Performance Management, Retention, Compensation

\section{Introduction}

\section{Steps for Effective Employee Recognition}

Employee recognition is not just a nice thing to do for people. Employee recognition is a communication tool that reinforces and rewards the most important outcomes that people create for your business. When you recognize people effectively, you reinforce, with your chosen means of recognition, the actions and behaviors that you most want to see people repeat. Your recognition reinforces the employee's understanding of how you would like to see him or her contributing to the workplace.

Since the majority of employees want you to see them as effective contributors, because it reinforces their own positive self-image, their self-worth, and self-esteem, your positive recognition is meaningful and supportive. An effective employee recognition system is simple, immediate, and powerfully reinforcing.

When you consider employee recognition processes, you need to develop employee recognition that is equally powerful for both the organization and the employee. It must make the employee feel recognized and rewarded in a powerfully positive way. Your employee recognition must also reinforce and ensure that you, the employer, will see a continuance of the positive behavior that was recognized.

You must address five important issues if you want your employees to view the recognition you offer as motivating and rewarding and important for the success of your organization. You need to establish criteria for what performance or contribution constitutes rewardable behavior or actions. By telling the employees the behavior that you want to see, you set them up for success and accomplishment.

- You need to make all employees eligible for the recognition. You should never exclude any employee or group of employees.

- The recognition must supply the employer and employee with specific information about what behaviors or actions are being rewarded and recognized. The more clearly you design and communicate the criteria for eligibility for the award, the easier it is for employees to perform accordingly. Since this is the performance you most want to see 
from employees, it's a plus for the employer if many employees attain eligibility.

- Anyone who then performs at the level or standard stated in the criteria receives the reward. Or, in an occasionally used approach especially when the affordability of the reward by the employer is a concern, every employee who meets the criteria has his or her name added to a drawing. You must communicate on the front end the fact that one name or three or however many employees you plan to reward will be selected randomly from among the employees who met the eligibility criteria.

- The recognition should occur as close to the performance of the actions as possible, so the recognition reinforces the behavior the employer wants to encourage. Monthly recognition is too infrequent and not reinforcing. Annual recognition, plaques, and gifts reinforce the performance you'd like to see even less effectively.

- You don't want to design a process in which managers select the people to receive recognition. Employees will see this type of process forever as managerial favoritism. Or, they will talk about the recognition in words such as, "Oh, it's your turn to get recognized this month." This is why processes that single out an individual, such as Employee of the Month, are rarely effective.

\section{Types of Reward Programs}

There are a number of different types of reward programs aimed at both individual and team performance.

- Variable Pay- Variable pay or pay-for-performance is a compensation program in which a portion of a person's pay is considered "at risk." Variable pay can be tied to the performance of the company, the results of a business unit, an individual's accomplishments, or any combination of these. It can take many forms, including bonus programs, stock options, and one-time awards for significant accomplishments. Some companies choose to pay their employees less than competitors but attempt to motivate and reward employees using a variable pay program instead. Good incentive pay packages provide an optimal challenge, one that stretches employees but remains in reach. If too much is required to reach the goal, the program will be ignored.

- Bonuses- Bonus programs have been used in American business for some time. They usually reward individual accomplishment and are frequently used in sales organizations to encourage salespersons to generate additional business or higher profits. They can also be used, however, to recognize group accomplishments. Indeed, increasing numbers of businesses have switched from individual bonus programs to one which rewards contribution to corporate performance at the group, departmental, or company-wide levels.

According to some experts, small businesses interested in long-term benefits should probably consider another type of reward. Bonuses are generally short-term motivators. By rewarding an employee's performance for the previous year, they encourage a short-term perspective rather than future-oriented accomplishments. In addition, these programs need to be carefully structured to ensure they are rewarding accomplishments above and beyond an individual or group's basic functions. Otherwise, they run the risk of being perceived as entitlements or regular merit pay, rather than a reward for outstanding work. Proponents, however, contend that bonuses are a perfectly legitimate means of rewarding outstanding performance, and they argue that such compensation can actually be a powerful tool to encourage future top-level efforts.

- Profit Sharing- Profit sharing refers to the strategy of creating a pool of money to be disbursed to employees by taking a stated percentage of a company's profits. The amount given to an employee is usually equal to a percentage of the employee's salary and is disbursed after a business closes its books for the year. The benefits can be provided either in actual cash or via contributions to employee's plans. A benefit for a company offering this type of reward is that it can keep fixed costs low.

- Stock Options- Previously the territory of upper management and large companies, stock options have become an increasingly popular method in recent years of rewarding middle management and other employees in both mature companies and start-ups. Employee stock-option programs give employees the right to buy a specified number of a company's shares at a fixed price for a specified period of time (usually around ten years). They are generally authorized by a company's board of directors and approved by its shareholders. The number of options a company can award to employees is usually equal to a certain percentage of the company's shares outstanding.

\section{Literature Review}

Unnikrishnan (2020) in banking sector, the rewards and recognition plays a prominent role in enhancing productivity while keeping the employees motivated. Takahashi et al (2017) Studies point out that financial rewards satisfy hygienic factors, pressure the organization's costs, and its impact on employee motivation is short-term. With respect to non-financial rewards, they claim to be complementary to the former, they are more widely adopted in budget constrained environments and an employee's choice factor when two companies offer the same compensation program. Recognition programs, which are strictly one of the 
non-financial reward forms, are aimed at reinforcing courageous behavior and exceptional efforts. Ghosh et al (2016) The variable rewards and recognition is found to be significantly correlated to both employee engagement and normative commitment. The relationship between rewards and recognition and normative commitment is found to become smaller after controlling the variable employee engagement. Bustamam et al (2014) The results revealed that rewards are positively and significantly associated with job satisfaction. In addition, the regression result has indicated that financial reward has a stronger impact on job satisfaction as compared to the non-financial reward. Hence, hypothesis 3: financial rewards affect job satisfaction was accepted while hypothesis 4 : non-financial rewards affect job satisfaction was rejected in the study. Malik et al (2015) The study proposes that extrinsic rewards for creativity positively predict creative performance only when employees have high creative self-efficacy and regard such rewards as important. Extrinsic rewards positively affect the intrinsic motivation of employees with an internal locus of control, thus enhancing their creative performance. Results based on a sample of 181 employee-supervisor dyads largely supported these expectations. The current analysis enriches the creativity literature by combining different perspectives in a coherent framework, by demonstrating the positive effects of extrinsic rewards on intrinsic motivation, and by demonstrating that the rewards-creativity relationship varies across employees depending on their individual differences.

Strand (2016) The findings confirm earlier research that Autonomy is one of the highest-ranked rewards for a knowledge worker but that affiliation is of equal or even higher importance. The result also indicates that the difference between knowledge workers and other kinds of workers with aspect to affiliation is low or even non-existent. The study has also shown that autonomy, praise/recognition and career/personal development is of far more importance for a knowledge worker than for other kinds of workers which may act as an important input to HR professionals. Mehta et al (2017) A series of five studies demonstrate that within the context of creativity contingency, monetary rewards induce a performance focus, while social-recognition rewards induce a normative focus. Such performance (normative) focus in turn enhances (attenuates) approach motivation to be original and hence leads to higher (lower) originality in a creative task. Thus, the study not only advances the current understanding of how and why two types of widely used creativity-contingent external rewards may have contrasting effects on creative performance, but it also offers important practical insights to managers who utilize reward systems in cultivating consumer creativity in their innovation platforms. Kilam \& Kumari (2012) Career growth and development needs a consciously planned effort on the part of the individual careerist and the same cannot be left to chance. Nearly $81 \%$ of respondents perceived that a well-established Private Sector in India and the foreign banks had better Career Planning \& HRD System as compared to that in Indian Public Sector Banks. Over the years and in tune with the changing times, Indian Public Sector Banks have reviewed their HR \& promotion policy and now for bright, hardworking and knowledgeable employees, it takes comparatively lesser time to move to higher levels in the banking hierarchy. This attitudinal change has to be on-going\& purposive. Kumari (2011) The study measured the level of employee satisfaction at Tata Steel. Training was the factor that contributed to employee satisfaction more than other factors. The other dimensions across which the employee satisfaction measured were Superior-Subordinate relationship, Role, Culture, Career Development, Goals and Motivation. Kosfeld et al (2017) Results show that workers exert more effort when the meaning is high. Money has a positive effect on performance that is independent of meaning. In contrast, meaning and recognition interact negatively. The results provide new insights into the stability of incentive effects across important work contexts. They also suggest that meaning and worker recognition may operate via the same motivational channel. Kumari (2013) Employees believe that the top management gives importance to human resource and all the employees are treated humanely in the organization. The climate is also favorable in terms of an employee being handled with care by seniors as they understand the mistake and do not take any strict disciplinary action such as punishing or discouraging. There is also a fair share of management involvement in making work enjoyable. A good part of Spanco regarding HRD is that top management understands the importance of human resource and actually translates that realization into day to day practice and HR policies. In conclusion, the overall HRD climate of Spanco is encouraging. There is a keen interest in top management in HRD and there is a high team spirit and employees take training seriously. The organizational belonging of employees is also high. Despite such a positive base for HRD, the HRD mechanism needs improvisation in a systematic way.

Van Dyke \& Ryan (2012) shows that top-performing organizations are using travel, merchandise and gift cards to augment current reward structures and impact near-term success. And they are doing so with great success. By following eight basic events in the design and implementation of non-cash reward and recognition programs, all organizations can build a cost-effective reward portfolio that captures the key talent and, most importantly, business results. Hussain et al (2019) the results support that job stress has a significant negative effect on the employees' performance while rewards and recognition have a significant positive effect on the employees' performance. Luo et al (2017) the online alignments model is able to start producing outputs without the need to first process the entire input sequence. A highly 
accurate online sequence-to-sequence model is useful because it can be used to build an accurate voice-based instantaneous translator. The designed model uses hard binary stochastic decisions to select the time steps at which outputs will be produced. The model is trained to produce these stochastic decisions using a standard policy gradient method. Long \& Shields (2010) Results indicate that non-cash plans are indeed common in both countries, but do not appear to substitute for cash-based performance plans, contrary to enthusiasts' suggestions. The most important predictor of non-cash programs is unionization, which is negatively related to both individually based and group-based NCR programs in Canada, and to group-based programs in Australia.

\section{Research Methodology}

\section{Objectives of the Study}

- $\quad$ To find out the extent to which reward and recognition practices are implemented in Sona Koyo Steering System Ltd.

- To understand whether reward and recognition programs really motivate and satisfy the employees.

\section{Data Collection}

The data includes both primary and secondary data. For the purpose, a structured questionnaire was drafted comprising of both open and closed ended questions. It had 21 items in total. For secondary data, various articles, books and websites were consulted the names of which are duly mentioned in the literature review and reference section.

\section{Sampling Technique}

The questionnaire was filled by the employees of Sona Koyo Steering System Ltd. who were selected on the basis of random sampling to achieve the knowledge of reward and retention programs in the organization.

\section{Area of study \& sample size}

The survey was conducted in Sona Koyo Steering System Ltd., Gurugram consisting population of about 70 employees, from different posts and designations, as well as from different departments. The sample size is 50 .

\section{Reward and Recognition System at Sona Koyo Steering Ltd.}

1. Yearly reward - This reward is given at the end of the year within the organization as a special recognition to the employees. This award is given on the basis of the performance and in this, the employee has to fill-up his quarterly performance appraisal form and submit it. The committee then gives a rating to its employee and on the basis of which the employee is rewarded.

The rewards the employees get are the following:

- Monetary term

- Non- monetary term e.g. gifts, dinner or lunch with executives, and holiday packages

- Increment in salary

- Promotion

2. Long service award policy - To acknowledge the long serving loyal employees of the company, a cash reward based on the years of the continuous service completed is awarded.

Eligibility- All the employees completing 5, 10, 11 years of service are eligible for it.

\section{Policy Specifications}

Table 1. Showing the policy specifications at Sona Steering Systems Ltd.

\begin{tabular}{|l|c|c|}
\hline Years of service & JM Grade & SM Grade \\
\hline 5 & Wrist watch worth Rs.1200/- \\
\hline 10 & 3500 \\
\hline 11 & 2000 \\
\hline 20 & Gold coin \\
\hline
\end{tabular}

\section{Conditions:}

- $\quad$ This award is given on the completion of continuous years of service with Sona Koyo.

- The final authority on all the decisions and discrepancies lies with the GM, HR and personnel manager.

- The employee is facilitated with a long service certificate on the day of completion of the eligibility period and an award payment is made on $1^{\text {st }}$ October.

- The employee is required to be on the payroll of the company on the $1^{\text {st }}$ of October to avail the long service award payment.

- The payment is made through cheque.

- The employee is required to submit the expense bill in lieu of the amount of the reward applicable.

3. Production incentives- Production incentives are performance-based incentives and are given with the salary. It depends on the units of production, if employee performs beyond his target, he gets some points and according to those points he gets incentives with the salary.

Applicability- Production incentives will be applicable to all the regular employees of Sona Koyo Steering System 
Ltd. at the operating level (i.e. S grade S1 to S6).

\section{Reward Scheme}

Reward scheme consists of the following five parts:

a. Efficiency linked (companywide)

b. Efficiency linked (line wise)

c. Quality linked

d. Profit linked

e. Attendance linked

a) Efficiency linked (Companywide)

- All plants 1,2 and 4 will be considered where a new product is being produced.

- Overall line efficiency will be calculated for each line by using the formula.

- Then overall plant efficiency will be calculated by using the formula.

- If the overall line efficiency of any line will be less than $40 \%$ then such lines will not receive any company wide efficiency linked reward.

- Overall plant efficiency will be calculated and rewarded each month.

b) Efficiency linked (Line wise)

- This reward is linked to the efficiency of each line, and reward is given based on the line efficiency of the line they are working on.

- Line efficiency and reward are calculated each month.

c) Quality linked

i. Customer return - Customer return for the company from all the customers is calculated every month.

ii. In house rejection- All in house rejection is calculated every month for the rewards.

d) Profit linked- This reward will be based on a percentage of the operating profit before depreciation, interest and tax (OPBDIT) for the previous year as compared to the net income from the previous year.

e) Attendance linked- Individual performance is measured in terms of the attendance in a month and payment is made accordingly.

\section{Suggestion Scheme}

The title for suggestion scheme of Sona Koyo is - "JO SOCHE VO PAVE"

Objectives of the scheme:

- To provide an opportunity to the employees to communicate their valuable ideas, creative thoughts, develop their talents and achieve costs reduction and increase the productivity.

- To share the benefits resulting from the adoption of such suggestions.
- To promote employees' motivation and boost their morale and give personal recognition.

- To imbibe the spirit of cooperation and teamwork among the employees at all levels within the organization.

Eligibility- All the employees including permanent, probationers and temporary are eligible for it.

\section{Procedure}

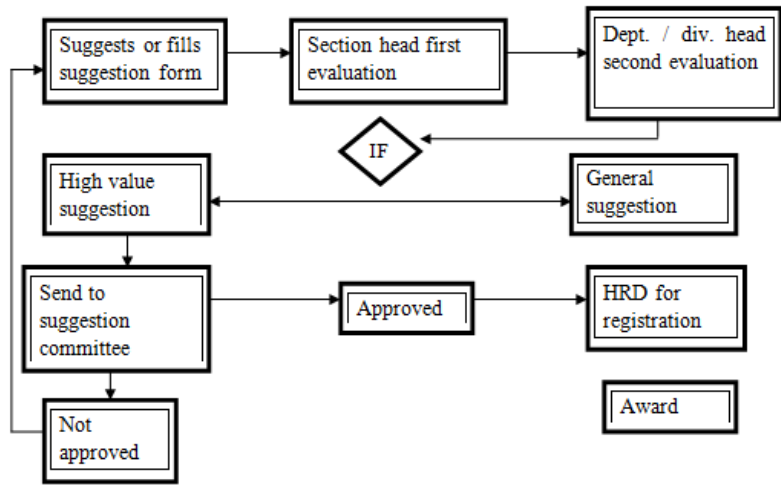

Figure 1. Procedure for getting award under the suggestion scheme

Suggestion Committee would decide the best suggestion of the month from the following categories:

- Productivity improvement

- Quality Improvement

- Downtime reduction

- Cost saving

i. Productivity improvement
a) Productivity improvement more than $2 \%=\mathrm{Rs}$ 900
b) Productivity improvement more than $3 \%=\mathrm{Rs}$ 1200
c) Productivity improvement more than $4 \%=$ Rs 1500
d) Productivity improvement more than $5 \%=$ Rs 1800

ii. Quality Improvement
a) Reduction in line overall rejection more than $10 \%$ $=$ Rs 900
b) Reduction in line overall rejection more than $15 \%=$ Rs 1200
c) Reduction in line overall rejection more than $20 \%=$ Rs 1500
d) Reduction in line overall rejection more than $25 \%=$ Rs 1800

iii. Downtime Reduction (individual head)
a) Downtime reduction up to $10 \%=$ Rs 600
b) Downtime reduction up to $15 \%=$ Rs 900
c) Downtime reduction up to $20 \%=$ Rs 1200
d) Downtime reduction up to $25 \%=$ Rs 1500 
Table 2. Showing the method of choosing the best suggestion from the " cost saving " category

\begin{tabular}{|c|c|c|}
\hline S.NO. & Marks obtained & Award Amount \\
\hline 1 & 35 & 60 \\
\hline 2 & 40 & 100 \\
\hline 3 & 50 & 150 \\
\hline 4 & 60 & 300 \\
\hline 5 & 70 & 500 \\
\hline 6 & 80 & 600 \\
\hline 7 & 90 & 900 \\
\hline 8 & 100 & 1200 \\
\hline 9 & 110 & 1500 \\
\hline 10 & 120 & 1800 \\
\hline 11 & 130 & 2000 \\
\hline
\end{tabular}

\begin{tabular}{|c|c|c|c|c|c|}
\hline Level & $\begin{array}{c}\text { Cost saving } \\
\text { in Rs }\end{array}$ & $\begin{array}{c}\text { Points (based } \\
\text { upon value) }\end{array}$ & $\begin{array}{c}\text { Excellent (it can be } \\
\text { applied all over the } \\
\text { plant company) }\end{array}$ & $\begin{array}{c}\text { Very good (it can be applied } \\
\text { in similar work processes) }\end{array}$ & $\begin{array}{c}\text { Fair (it can be applied only in } \\
\text { suggestors' own work area) }\end{array}$ \\
\hline A & $\begin{array}{c}100001 \sim 200000 \\
\& \text { above }\end{array}$ & 70 & 60 & 50 & 40 \\
\hline B & $50001 \sim 100000$ & 60 & 50 & 40 & 30 \\
\hline C & $25001 \sim 500000$ & 50 & 40 & 30 & 20 \\
\hline D & $10001 \sim 25000$ & 40 & 20 & 10 & 5 \\
\hline E & $5001 \sim 10000$ & 30 & & & 5 \\
\hline F & $1000 \sim 5000$ & & & & \\
\hline
\end{tabular}

\section{iv. Cost saving}

Suggestion committee would select the three best suggestions from the following categories for the best suggestion of the year:

- Productivity improvement

- Quality improvement

- Downtime reduction

- Cost saving

- Maximum number of individual suggestion

Award for the first position $=$ Rs 3000

Award for the second position $=$ Rs 2000

Award for the third position $=$ Rs 1500

\section{Analysis and Interpretations}

Q1. My organization rewards me for my performance.

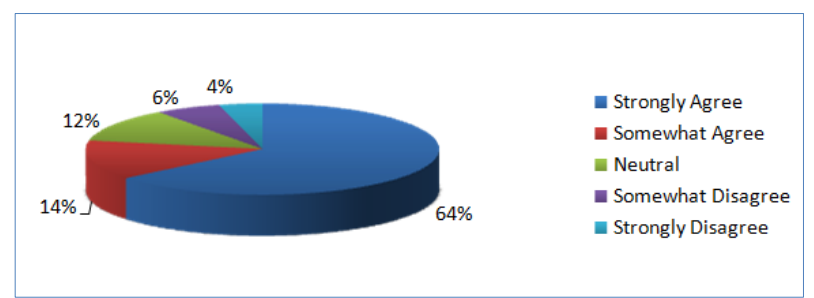

Figure 2. Showing responses for $\mathrm{Q} 1$

Interpretations: The pie chart represents that about $64 \%$ of respondents strongly agree with the statement, so it means that most of the organizations reward their employees for their performance.

Q2. Reward scheme is budgeted every financial year in my organization.

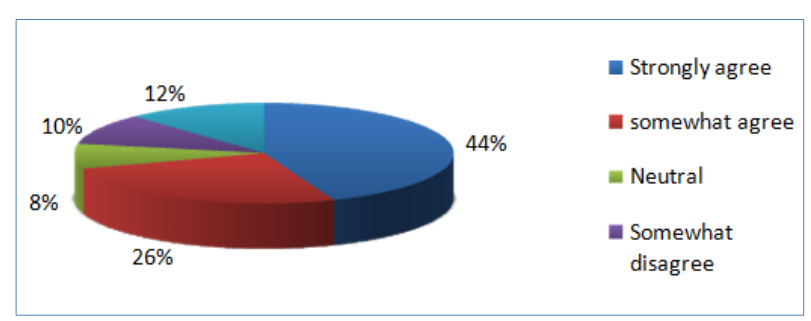

Figure 3. Showing responses for Q2

Interpretations: Around $44 \%$ of the respondents strongly agree to the statement that their organization budget their reward scheme in every financial year. While a few respondents i.e. around $10 \%$ said that it's not necessary that it's budgeted every financial year.

Q3. I get satisfied by the monetary reward of my company.

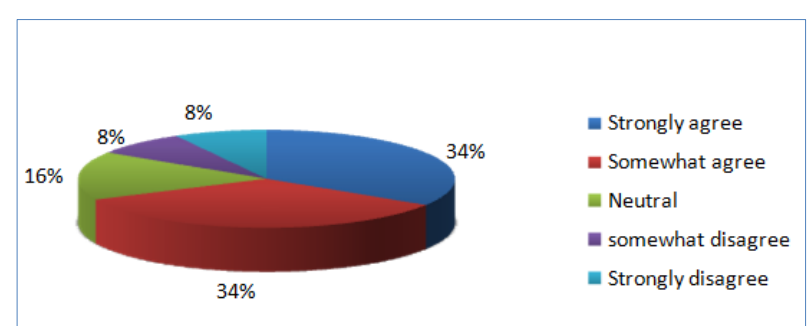

Figure 4. Showing responses for Q3 
Interpretations: Around $34 \%$ of the respondents strongly agree but on the other hand, around $34 \%$ of the respondents somewhat agree with the statement that they get satisfied with the monetary rewards. This shows that they are motivated by the monetary reward.

Q4. Reward and recognition is incurred as a cost to the company.

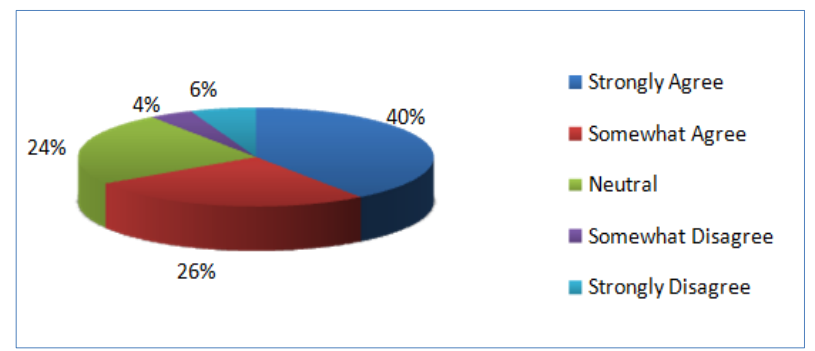

Figure 5. Showing responses for Q4

Interpretations: Most of the respondents i.e. around $40 \%$ strongly agree with the statement that the rewarding employees are incurred as a cost to the company.

Q5. Reward and recognition are the best way to motivate the employees.

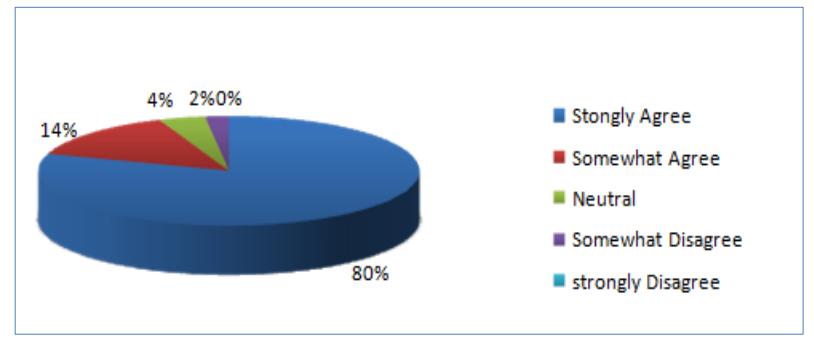

Figure 6. Showing responses for Q5

Interpretations: Around $80 \%$ of the respondents strongly agree with the statement that the reward and recognition is the best way to motivate the employees.

Q6. Reward system practiced in my organization is transparent and communicated to all.

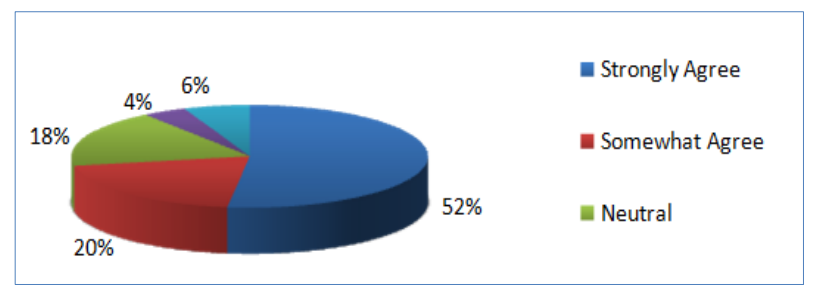

Figure 7. Showing responses for Q6

Interpretations: Around 52\% of the respondents strongly agree with the statement that transparency is maintained with regard to reward and recognition system of their organization.

Q7. Reward and recognition is helpful in retaining the talented workforce.

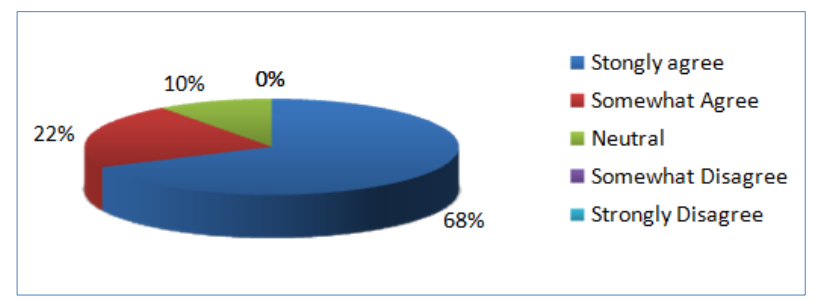

Figure 8. Showing responses for Q7

Interpretations: Reward and recognition is the best way of retaining the talented workforce as most of the respondents i.e. around $68 \%$ are in strong agreement with the statement.

Q8. Reward and recognition program is effective in increasing the employee productivity.

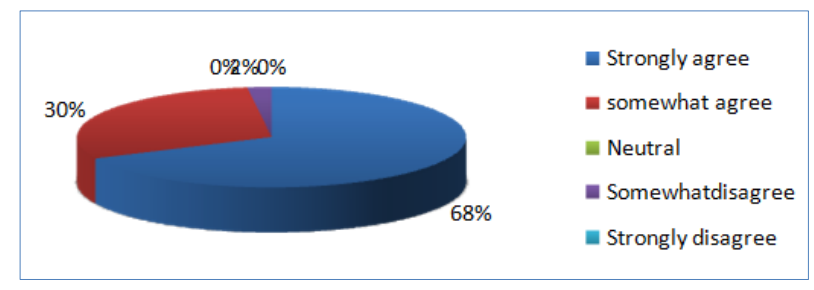

Figure 9. Showing responses for Q8

Interpretations: Around $68 \%$ of the respondents strongly agree with the statement that their productivity increases with the implementation of an effective reward and recognition system.

Q9. All the employees are eligible for the reward in my organization.

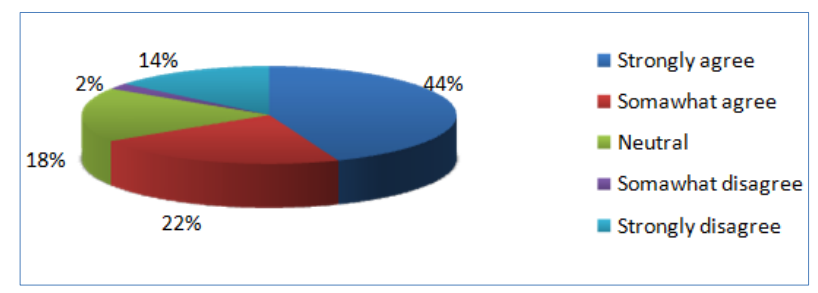

Figure 10. Showing responses for $\mathrm{Q} 9$

Interpretations: Around $44 \%$ of the respondents strongly agree and around $22 \%$ of the respondents somewhat agree with the statement that all the employees are eligible for the rewards.

Q10. Performance based reward affects the performance of the other employees.

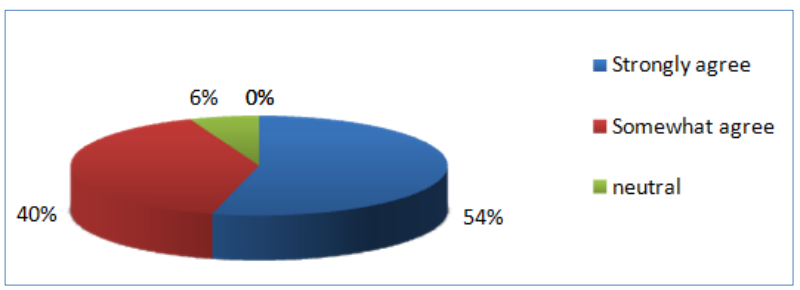

Figure 11. Showing responses for Q10 
Interpretations: The pie chart shows that rewarding on the basis of performance affects the productivity of other employees.

Q11. Rewarding employee's family (scholarship for meritorious children of employees) motivates the employees.

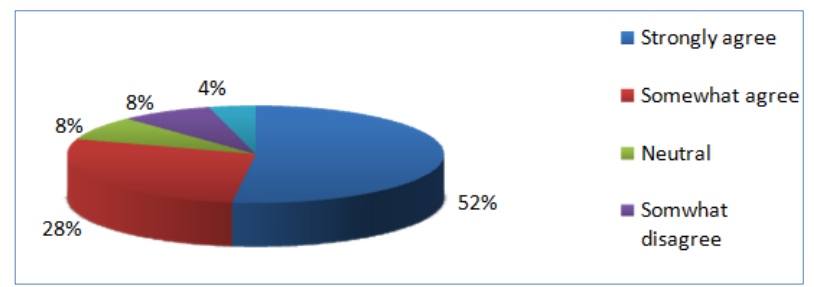

Figure 12. Showing responses for Q11

Interpretations: Around 52\% of the employees strongly agree with the statement that rewarding employee's family affects the performance of the employee. While around $12 \%$ of the employees somewhat or strongly disagree with the same statement.

Q12. My organization provides a long service award.

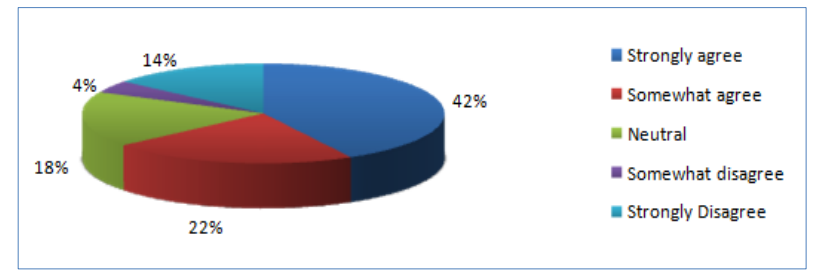

Figure 13. Showing responses for $\mathrm{Q} 12$

Interpretations: Around $42 \%$ of the respondents strongly agree with the statement that their organization provides a long service award. But from the pie chart, it can be concluded that every organization does not provide long service awards to its employees.

Q13. My organization rewards for suggestion which contributes to the objective of the organization.

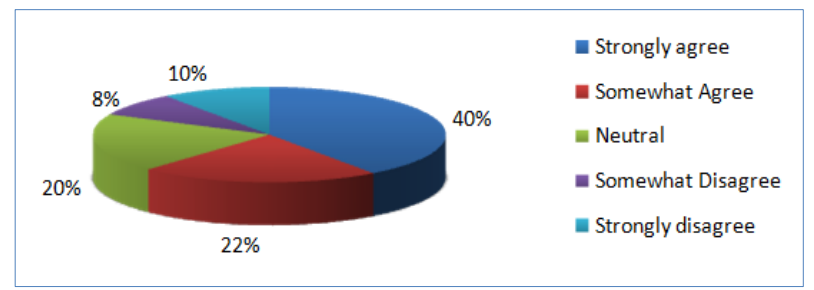

Figure 14. Showing responses for Q13

Interpretations: Around $40 \%$ of the respondents strongly agree with the statement that their organization rewards the employees for suggestions which contribute to the objective of the organization. While only a few respondents i.e. around $10 \%$ strongly disagree with the same statement.

Q14. What type of reward policy is implemented in your organization?

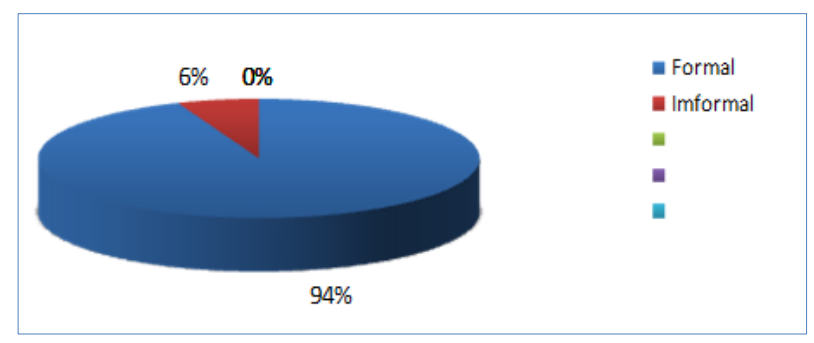

Figure 15. Showing responses for Q14

Interpretations: Almost every organization follows the formal reward policy.

Q15. What type of reward system is in your organization?

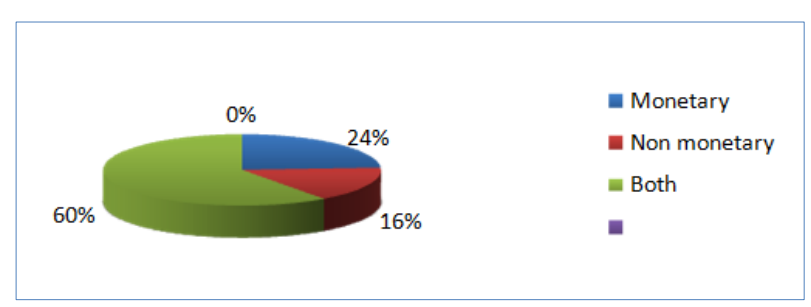

Figure 16. Showing responses for Q15

Interpretations: Most of the organizations adopt monetary and non- monetary reward systems.

Q16.Among these non-monetary rewards, rate them on 1-6 in order of your preference.

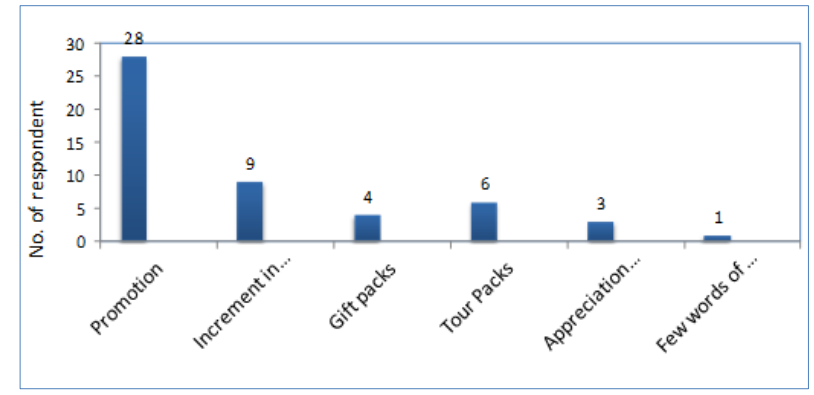

Figure 17. Showing responses for Q16

Interpretations: The first preference of most of the employees is a non- monetary reward i.e. promotion. And the second preference is an increment in benefits.

Q17.What is the frequency of reward in your organization?

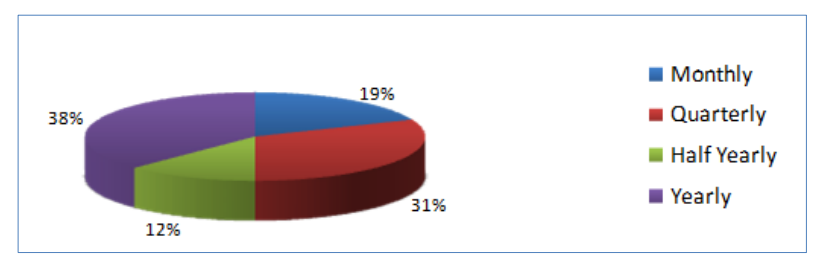

Figure 18. Showing responses for Q17

Interpretations: Around $38 \%$ of the respondents are rewarded yearly while around $31 \%$ of the respondents are 
rewarded quarterly in the organization.

Q18.In your organization, employees are considered for reward and recognition mostly for?

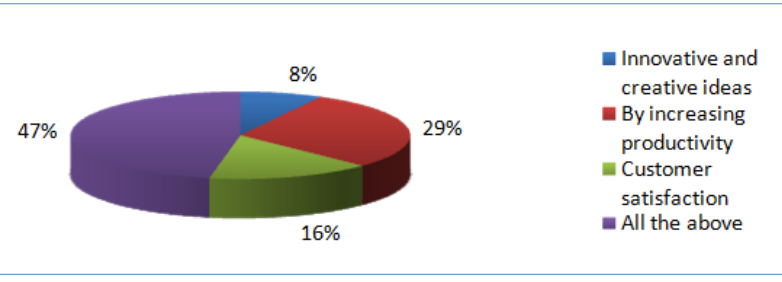

Figure 19. Showing responses for Q18

Interpretations: A large portion of the respondents i.e. around $47 \%$ of the respondents said that the organization rewards them for attributes like innovative and creative ideas, for increasing productivity as well as for customer satisfaction.

Q19. How is the employee selected for the reward in your organization?

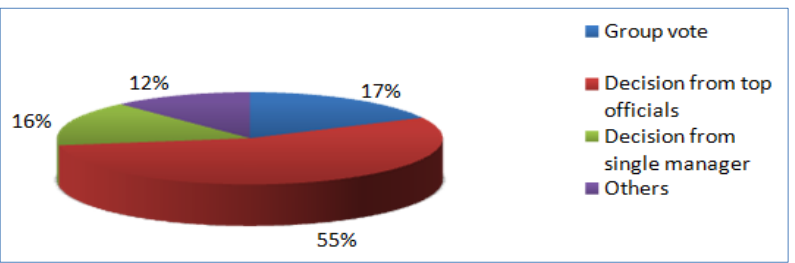

Figure 20. Showing responses for Q19

Interpretations: Most of the respondents agree to the statement that their reward decisions are taken by the top officials.

Q20. If there is no improvement in the performance of the employee then the organization would-

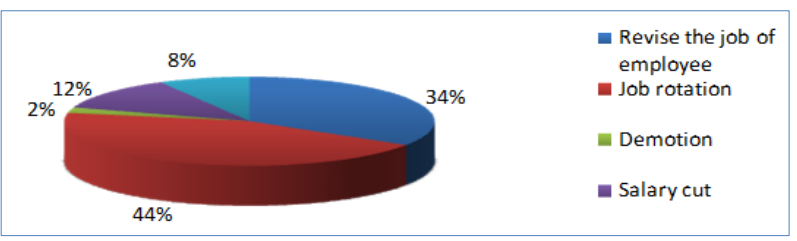

Figure 21. Showing responses for Q20

Interpretations: In the majority of the cases, the organization rotates the job of the employees in order to attain improvements in the performance of the employees.

Q21. What is the best way of recognition?

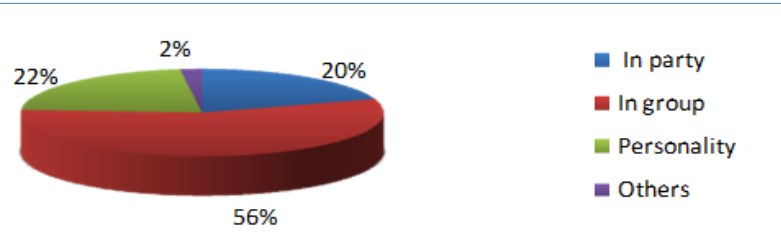

Figure 22. Showing responses for Q21
Interpretations: Most of the respondents said that the best way to recognize the employees is in the group.

\section{Findings}

Following are the findings of the study:

- Contractual employees and trainees are not covered in the reward policy.

- The impact of performance-based reward is positive as well as negative on the employees.

- In a few cases, the organization rewards their employee's family in order to motivate the employees.

- The organization provides long service awards to the employees for appreciating their services and long association with the organization.

- The organization provides reward for the best suggestions given by the employees which help in the reduction of the cost or increase in profit.

- The reward policy of the organization is published in their HR manual.

- The organization provides both types of rewards; monetary and non-monetary, but nowadays most of the organizations are giving non-monetary rewards like promotion, increment in benefits, gift packs and so on because these are highly preferred by the employees.

- The organization fixes $10 \%$ to $15 \%$ of its revenue for reward and recognition.

- Decisions from the top officials are considered for the employee selection for reward.

- Rotation of the job is done in the organization so as to improve the performance of the employee.

- The best way to recognize the employees is in the group.

\section{Recommendations}

- All the levels of the employee must be rewarded for their performance so as to increase their interest and work efficiency.

- The recognition should occur as close to the performance of the actions as possible so the recognition reinforces the behavior the employer wants to be encouraged.

- The employee should immediately be rewarded for the work well done.

- There must be transparency and immediate decision making should be followed.

- The organization should give verbal appreciation for the work well done because it is one way to reward and it also motivates the employees. 


\section{Conclusions}

Few innovative ways of rewarding the employees are: Motivational poster for recognition, engraved articles for excellence and good teamwork, giving a gift like a pen, lapel pins, desk clock, etc. which consist of some appreciable words written to all the individuals in the team, Thank you gifts to please the individual tastes.

Gifts can include crystal picture frame, watches, best wishes bowl and a memorable picture frame saying "THANK YOU" in truly memorable fashion, Gift certificates - In this, the employer can ask the employee to shop from a local store by giving him a certificate which represents a certain amount of cash. The employer should take care of the basic needs of the employees.

\section{REFERENCES}

[1] Bustamam, F. L., Teng, S. S., \& Abdullah, F. Z. (2014). Reward management and job satisfaction among frontline employees in hotel industry in Malaysia. Procedia-Social and Behavioral Sciences, 144, 392-402.

[2] Ghosh, P., Ghosh, P., Rai, A., Rai, A., Chauhan, R., Chauhan, R., ...\& Srivastava, D. (2016). Rewards and recognition to engage private bank employees: Exploring the "obligation dimension”. Management Research Review, 39(12), $1738-1751$.

[3] Hussain, S. D., Khaliq, A., Nisar, Q. A., Kamboh, A. Z., \& Ali, S. (2019). The Impact of Employees' Recognition, Rewards and Job Stress on Job Performance. SEISENSE Journal of Management, 2(2), 69-82.

[4] Kilam, I. K., \&Kumari, N. (2012). Career planning and HRD Climate-A major HR challenge for public sector banks in India. Asian Journal of Multidimensional Research, 1(7), 60-82.

[5] Kosfeld, M., Neckermann, S., \& Yang, X. (2017). The effects of financial and recognition incentives across work contexts: the role of meaning. Economic Inquiry, 55(1), 237-247.

[6] Kumari, N. (2011). A Live Study of Employee Satisfaction and Growth Analysis: Tata Steel. European Journal of Business and Management, 3(10), 53-62.

[7] Kumari, N. (2013). Factors Influencing the HRD Climate of an Organization. International Journal of Management and Sustainability, 2(10), 156.

[8] Long, R. J., \& Shields, J. L. (2010). From pay to praise? Non-cash employee recognition in Canadian and Australian firms. The International Journal of Human Resource Management, 21(8), 1145-1172.

[9] Luo, Y., Chiu, C. C., Jaitly, N., \& Sutskever, I. (2017, March). Learning online alignments with continuous rewards policy gradient. In Acoustics, Speech and Signal Processing (ICASSP), 2017 IEEE International Conference on (pp. 2801-2805). IEEE.

[10] Malik, M. A. R., Butt, A. N., \& Choi, J. N. (2015). Rewards and employee creative performance: Moderating effects of creative self-efficacy, reward importance, and locus of control. Journal of Organizational Behavior, 36(1), 59-74.

[11] Mehta, R., Dahl, D. W., \& Zhu, R. (2017). Social-Recognition versus Financial Incentives? Exploring the Effects of Creativity-Contingent External Rewards on Creative Performance. Journal of Consumer Research, ucx062.

[12] Strand, L. O. (2016). Retaining Knowledge Workers: A ranking of the most valuable Rewards.

[13] Takahashi, T., Neto, M. T. R., \& Togashi, F. E. (2017) Relevant factors in the implementation of non-financial rewards and recognition programs. Revista De Gestao, Financas E Contabilidade, 7(3), 247-264.

[14] Unnikrishnan, A. (2020). A study on impact of rewards and recognition on employee performance. Purakala, 31(4), 2352-2369.

[15] Van Dyke, M., \& Ryan, M. (2012). Changing the compensation conversation and the growing utility of noncash rewards and recognition. Compensation \& Benefits Review, 44(5), 276-279. 